\title{
CONTRIBUIÇÕES DO PIBID NA FORMAÇÃO DOCENTE: ENUNCIAÇÕES DE UMA “PIBIDIANA”
}

\author{
Sabrina Monteiro ${ }^{1}$, Ieda Maria Giongo ${ }^{2}$, Luis Felipe Pissaia ${ }^{3}$, Mateus Lorenzon ${ }^{4}$, \\ Silvana Neumann Martins ${ }^{5}$
}

Resumo: Este trabalho apresenta uma reflexão sobre as contribuições decorrentes do Programa Institucional de Bolsa de Iniciação à Docência (PIBID) na formação docente alusivas à enunciações de uma "Pibidiana". A importância da formação inicial e continuada de professores é cada vez mais discutida e problematizada no contexto educacional brasileiro. Ademais, está diretamente relacionada com as constantes modificações que as Políticas Públicas voltadas para a formação de professores vêm passando nos últimos anos. Para tanto, neste texto foram usadas ideias de autores que tratam dessa temática, como Nóvoa (2009), Ghedin (2009), Felício (2014), Marques (2015) entre outros. O objetivo deste estudo é discutir PIBID para o processo de formação docente. O Programa tem se consagrado como uma proposta de valorização e aperfeiçoamento dos futuros docentes durante seu processo de formação, na qual é possível inferir que ele está atingindo seus objetivos como Política Pública de formação de professores e qualificação da escola básica.

Palavras-chave: PIBID. Formação Docente. Políticas Públicas. Ensino. Escola.

\section{PIBID CONTRIBUTIONS IN TEACHING TRAINING: ENSERVATIONS OF A "PIBIDIANA"}

Abstract: This paper presents a reflection on the contributions of the Institutional Program of the Initiation to Teaching Grant (PIBID) in the teaching formation alluding to the enunciations of a "Pibidiana". The importance of initial and continuing teacher training is increasingly discussed and problematized in the Brazilian educational context. In addition, it is directly related to the constant changes that the Public

1 Graduada em Ciências Exatas. Mestranda em Ensino. Universidade do Vale do Taquari - Univates. Bolsista contemplada com Taxa PROSUP/CAPES. E-mail: sabrinamonteiro1991@gmail.com

2 Doutora em Educação (Unisinos), Professora da Graduação e Pós-Graduação (Mestrado e Doutorado em Ensino e Ciências Exatas - Univates).

3 Graduado em Enfermagem. Mestrando em Ensino. Universidade do Vale do Taquari - Univates. E-mail:1pissaia@universo.univates.br

4 Graduado em Pedagogia. Mestrando em Ensino. Universidade do Vale do Taquari - Univates. E-mail: mateusmlorenzon@gmail.com

5 Doutora em Educação. Universidade do Vale do Taquari - Univates. E-mail: smartins@univates.br 
Policies directed towards the formation of teachers have been passing in recent years. For this purpose, we have used ideas from authors that deal with this theme, such as Nóvoa (2009), Ghedin (2009), Felício (2014), Marques (2015) and others. The purpose of this study is to discuss PIBID for the teacher training process. The Program has been consecrated as a proposal for enhancement and improvement of the future teachers during its training process, in which it is possible to infer that it is reaching its objectives as Public Policy of teacher training and qualification of the basic school.

Keywords: PIBID. Teacher Training. Public policy. Teaching. School.

\section{INTRODUÇÃO}

O presente artigo é resultado dos estudos e discussões ocorridos durante o desenvolvimento da disciplina de Políticas Públicas Educacionais do Programa de Mestrado Acadêmico de Ensino, promovido pela Universidade do Vale do Taquari UNIVATES. Partindo das considerações sobre Políticas Públicas, surgiu o interesse de criar uma reflexão acerca das contribuições decorrentes do Programa Institucional de Bolsa de Iniciação à Docência (PIBID) na formação do futuro professor.

Conforme Marques (2015) a relevância desta temática no cenário educacional está relacionada com as constantes modificações que as Políticas Públicas voltadas para a formação de professores vêm passando nos últimos anos. Uma vez que a dicotomia entre a teoria e a prática ainda é um problema encontrado em muitos cursos de Licenciatura, dessa forma o PIBID, com suas concepções, veio a se tornar referência nas Políticas Públicas, uma vez que oportuniza a aproximação do licenciando experiências da prática docente, valorizando assim a escola.

Ademais, destaca-se o enaltecimento proporcionado pelo Programa na produção de conhecimento na formação inicial docente, na qual verifica-se o licenciando tornandose protagonista na sua própria formação, através de concepções de investigação na sua ação. Essa experiência também oportuniza o trabalho colaborativo e as reflexões sobre as práticas desenvolvidas, com a finalidade de produzir novos saberes.

Em consonância a isso Braibante (2012) destaca que o PIBID é um projeto que tem se consolidado como uma iniciativa importante no que diz respeito à formação inicial dos acadêmicos das licenciaturas e vem preencher uma lacuna existente na maioria dos currículos entre a teoria e a prática docente, para o desenvolvimento de projetos na área de ensino. Assim sendo, acredita-se que, as Políticas Públicas voltadas à formação de professores, precisam ser foco de investigação. Partindo desse pressuposto, o objetivo deste estudo, é discutir alguns aspectos da relação entre formação de professores e a influência do PIBID.

Esse artigo assume um caráter reflexivo, uma vez que nele propõe-se analisar a importância do PIBID para o processo de formação docente. O Programa surgiu com um viés na preocupação da qualidade de formação dos professores, que acaba por se refletir no ensino que se tem atualmente e, consequentemente, com a situação real da educação básica pública. O PIBID oportuniza aproximações do aluno de licenciatura 
frente a situações concretas desempenhadas em sala de aula. Além disso, conforme Felício (2014) ele institui como uma possibilidade de articulação entre a teoria e a prática ao longo do processo de formação inicial.

Na primeira seção de estudo, denominada "Perspectivas do PIBID na formação docente inicial" problematiza-se sobre a formação docente, apoiada nos seguintes autores: Pérez Gomez (1992), Delors (1996), Ghedin (2009), Nóvoa (2009), Felício (2014) e Marques (2015). Em seguida "PIBID enquanto Política Pública" discute-se o embasamento legal deste Programa. Após, "Enunciações de uma Pibidiana" discorrese de reflexões e vivências de uma bolsista nas teorizações de Tardif (2012) e Nóvoa (1992-1995-2009). E por último faz-se as considerações finais, destacando o quanto esse Programa oportuniza de aprendizagem e conhecimento ao licenciando.

\section{PERSPECTIVAS DO PIBID NA FORMAÇÃO DOCENTE INICIAL}

Nesta seção evidencia-se o PIBID enquanto oportunidade da iniciação à docência, uma vez que a magnitude referente a formação inicial é cada vez mais discutida e problematizada no contexto educacional brasileiro. Ela está diretamente relacionada com as constantes modificações que as Políticas Públicas de formação docente vêm passando nos últimos anos. Segundo Pérez Gómez (1992), a formação, o desempenho e o desenvolvimento profissional do professor estão no centro dos debates e discussões sobre os rumos da educação.

A partir da década de 1990 configuraram-se novas tendências mundiais para a educação. Com isso surgiu alguns questionamentos em âmbito nacional em relação a prática docente realizada no cotidiano escolar, onde via-se um distanciamento desta com as teorias educacionais presentes nos currículos da formação inicial de professores. Delors (1996) já apontava que o século XXI submeteria a educação a uma difícil tarefa. À primeira vista contraditória, que é, de um lado, transmitir, de fato, de forma maciça e eficaz, cada vez mais saberes e saber-fazer evolutivos, adaptados à sociedade cognitiva, pois seriam as bases das competências do futuro. E, de outro, impedir que as pessoas fiquem submersas nas ondas de informações e levá-las a orientar-se para projetos de desenvolvimento individual e coletivo.

Esse mesmo autor evidencia a construção de educação ao longo da vida como um passaporte para o século XXI, destacando que, para dar resposta ao conjunto de suas missões, a educação deve estar organizada em torno de quatro aprendizagens fundamentais que, serão os pilares do conhecimento para cada indivíduo: aprender a conhecer, aprender a fazer, aprender a conviver e aprender a ser.

Aprender a conhecer refere-se ao conhecimento, entretanto, essa aprendizagem não deve se limitar à aquisição de um repertório de saberes, mas sim, "[...] aprender a aprender, para beneficiar-se das oportunidades oferecidas pela educação ao longo da vida" (DELORS, 1996, p. 31). Aprender a fazer relaciona-se mais as questões 
referentes à formação profissional. Aprender a conviver desenvolve a compreensão do outro. E por sua vez, conforme Delors (1996), aprender a ser leva em consideração todas as potencialidades do indivíduo, para que assim seja possível estar em condições de agir com uma capacidade cada vez maior de autonomia, discernimento e responsabilidade pessoal.

Em relação à formação do professor, Ghedin (2009) teoriza que ela deve ser fundamentada em cinco princípios. O primeiro princípio refere-se à dimensão ética, pois "[...] o ser professor está imbuído de um conjunto de valores e de práticas que servem como inspiração, como referência, são formativas dos alunos" (GHEDIN, 2009, p. 23). Seguido a uma prática ética, o professor possui, para o autor, um compromisso político, uma vez que "[...] o ato pedagógico é também político" (GHEDIN, 2009, p. 24). Como terceira dimensão, o autor cita a dimensão epistemológica, visto que o professor precisa dominar os conceitos da área de conhecimento em que atua.

A outra dimensão relaciona-se à técnica, que se refere ao domínio dos procedimentos e métodos de ensino e de aprendizagem, para o autor, o professor precisa perceber como conduzirá o processo de aprendizagem. Por fim, Ghedin (2009, p. 25) destaca a dimensão estética, já que "[...] não somos feitos apenas por racionalidade, mas também por sonhos, carinhos, afetividade e emoções”, características essas que andam indissociáveis na docência.

A formação de professores no Brasil passa por diversas reformas que buscam uma melhoria na qualidade dos processos de ensino e de aprendizagem. As Políticas Públicas estão articuladas com essa preocupação a partir do lançamento de propostas do Ministério da Educação e Cultura, dentre as quais se destaca o PIBID, cujo o enfoque está na inserção do futuro docente no contexto das escolas públicas do país. Ademais, as Políticas Públicas preocupam-se com a elevação dos níveis de qualidade no ensino, dessa forma o PIBID é uma importante política de formação de professores em âmbito nacional e que vem ganhando destaque nos últimos anos (MARQUES, 2015).

$\mathrm{Na}$ conjuntura atual, segundo Felício (2014) a sociedade contemporânea atribuiu de forma cada vez mais crescente responsabilidades, ao sistema educacional escolar e aos professores, decorrentes das transformações no mundo do trabalho, na revolução didática e nas relações sociais. Essas conexões tem provocado mudanças nas propostas educacionais, na atuação docente. Como consequência, vem se reconfigurando a identidade profissional docente, fragilizando, dessa forma, o processo de formação inicial de professores.

A partir dessas acepções, referindo-se a formação inicial de professores, Felício (2014) salienta que torna-se essencial combinar a formação acadêmica e a formação pedagógica, a fim de capacitá-los para o exercício de uma atividade que não se restringe, exclusivamente, a "ministrar aulas". O PIBID, ao oportunizar o espaço da escola como local de conhecimento para os licenciandos, potencializa a construção do saber pedagógico antes mesmo do efetivo exercício da profissão. Ao inseri-los nas escolas, Marques (2015) destaca que o Programa busca proporcionar-lhes práticas docentes 
com características inovadoras e interdisciplinares que apontem para a superação de problemas no processo de ensino e aprendizagem.

Ainda sobre a formação inicial dos professores, segundo Nóvoa (2009) pressupõe que esta deve contribuir no sentido de oferecer subsídios para o enfrentamento dos desafios colocados atualmente aos docentes, e de que essa formação deve ir além dos conteúdos teóricos. O mesmo, salienta que a contemporaneidade exige dos professores capacidade de contextualizar a escola para que ela assuma seu papel social e, assim, valorizar aquilo que é de sua competência, a saber, a formação humana. Nesse contexto, faz-se necessário repensar o papel da escola e os desafios a serem superados para que ela se torne sempre mais atrativa e proporcione ao estudante um ambiente mais envolvente, no qual ele possa desenvolver suas habilidades cognitivas e aprender de maneira diferente os conhecimentos que são pertinentes à sua vida e aqui entra o papel do PIBID.

\title{
PIBID ENQUANTO POLÍTICA PÚBLICA
}

Nesta seção, será discutido o embasamento teórico o qual sustenta esse Programa enquanto Política Pública. Primeiramente, cabe destacar que as Políticas Públicas correspondem a direitos assegurados constitucionalmente, nesta perspectiva, Souza (2003, p. 13) conceitua:

\begin{abstract}
[...] campo do conhecimento que busca, ao mesmo tempo, "colocar o governo em ação" e/ou analisar essa ação (variável independente) e, quando necessário, propor mudanças no rumo ou curso dessas ações e/ou entender por que e como as ações tomaram certo rumo em lugar de outro (variável dependente). Em outras palavras, o processo de formulação de política pública é aquele através do qual os governos traduzem seus propósitos em programas e ações, que produzirão resultados ou as mudanças desejadas no mundo real.
\end{abstract}

Partindo dessas acepções, surge o PIBID criado pela Coordenação de Apoio e Pessoal de Nível Superior (CAPES), tendo como embasamento legal a Lei ${ }^{\circ}$ 9.394/1996, que estabelece as Diretrizes e Bases da Educação Nacional. Também a Lei 11.273/2006, que autoriza a concessão de bolsas de estudo e de pesquisa a participantes de programas de formação inicial e continuada de professores para a educação básica. Esse Programa foi lançado pelo Ministério da Educação (MEC) por intermédio da Coordenação de Aperfeiçoamento de Pessoal de Nível Superior (CAPES), através da Portaria Normativa no 38 de 12 de dezembro de 2007, que visa contribuir com a elevação da qualidade da formação docente oferecida em nível superior e na valorização da sua prática.

No princípio, em 2007, evidencia-se que a proposta do Programa era propor a formação inicial a licenciando da área da Química, Física, Matemática e Biologia, por considerar a carência de professores nesta área, segundo Silva e Nunes (2016). No ano 
seguinte, incluiu-se o Programa nos cursos de Pedagogia. Já em 2010, foram criados editais que passaram a abranger ainda mais cursos, como história, geografia e também PIBID Diversidade, que relaciona-se à educação no campo e também à indígena. Em setembro deste mesmo ano, a Instituição a qual a "Pibidiana" pertencia, aderiu ao Programa e iniciaram-se os estudos e algumas ações que o propunha.

À medida que o PIBID viabiliza a inserção do licenciando em situações concretas nas quais se desenvolve o trabalho docente, ele permite aproximações fundamentais entre as dimensões que necessariamente se articulam enquanto o professor constrói seus saberes, oportunizando a prática dos saberes adquiridos na Universidade. Conforme consta no art. $4^{\circ}$ do seu regulamento - Anexo I da Portaria Capes no 96, de 18 de julho de 2013 -, o PIBID tem como principais objetivos:

I - Incentivar a formação de docentes em nível superior para a educação básica;

II - Contribuir para a valorização do magistério;

III - Elevar a qualidade da formação inicial de professores nos cursos de licenciatura, promovendo a integração entre educação superior e educação básica; IV - Inserir os licenciandos no cotidiano de escolas da rede pública de educação, proporcionando-lhes oportunidades de criação e participação em experiências metodológicas, tecnológicas e práticas docentes de caráter inovador e interdisciplinar que busquem a superação de problemas identificados no processo de ensino e aprendizagem;

V - Incentivar escolas públicas de educação básica, mobilizando seus professores como co-formadores dos futuros docentes e tornando-as protagonistas nos processos de formação inicial para o magistério;

VI - Contribuir para a articulação entre teoria e prática necessárias à formação dos docentes, elevando a qualidade das ações acadêmicas nos cursos de licenciatura; VII - Contribuir para que os estudantes de licenciatura se insiram na cultura escolar do magistério, por meio da apropriação e da reflexão sobre instrumentos, saberes e peculiaridades do trabalho docente;

VIII - Articular-se com os programas de formação inicial e continuada de professores da educação básica, de forma a contribuir com a criação ou com o fortalecimento de grupos de pesquisa que potencialize a produção de conhecimento sobre ensinar e aprender na Educação Básica;

IX - Comprometer-se com a melhoria da aprendizagem dos estudantes nas escolas onde os projetos institucionais são desenvolvidos (BRASIL, 2013).

Percebe-se que os objetivos são específicos e claros, voltados a participação ativa do licenciando na docência, oportunizando vivências no universo da sala de aula. Cabe evidenciar também sobre a importância na reflexão e na ação destas intervenções realizadas principalmente durante a formação inicial, como forma de contribuir para as próximas práticas a serem desenvolvidas. Neste contexto, Imbernón (2004) faz aproximações que vem de encontro com os objetivos que são propostos, o qual enfatiza que o processo de formação docente deve desenvolver a capacidade de tornar professores reflexivos e investigativos.

Dessa forma, além do Programa conceder bolsas de iniciação à docência, as quais incentivam os licenciandos a dedicar-se mais no processo formativo da futura profissão. 
É concedido bolsas para coordenador institucional, coordenador de área, supervisor da educação básica, portanto ratifica-se também a promoção de diálogo e troca de experiências entre os envolvidos, sem falar nas contribuições para a Universidade e também para as escolas de Educação Básica.

\section{ENUNCIAÇÕES DE UMA PIBIDIANA}

Nesta seção apresenta-se enunciações de uma Pibidiana, a qual é autora deste estudo. Esta, teve experiência proporcionada por esse Programa por quase cinco anos, no subprojeto das Ciências Exatas, oferecido na Instituição que estudava. Durante esse tempo, teve diversas vivências que oportunizaram momentos de aprendizagem, dentre estas, ela elencou algumas enunciações a serem discutidas a seguir.

A aproximação dos discentes com a realidade escolar nos cursos de licenciatura, anteriormente ficava restrito ao momento do estágio curricular ofertados pelas universidades. Com isso, surgiram às políticas de iniciativas, visando fortalecer essa aproximação do discente com o seu futuro campo de atuação. $O$ trabalho coletivo ou docência colaborativa oportuniza o compartilhamento de experiências, troca de informações e crescimento pessoal. Nesse sentido, Nóvoa $(1995$, p. 18) afirma que, “[...] mais do que um lugar de aquisição de técnicas e de conhecimentos, a formação de professores é o momento-chave de socialização e da configuração profissional".

A prática pedagógica constitui-se como um processo de vivência das teorias e concepções de cada professor no exercício de sua profissão. Ela passa por transformações na medida em que o professor assume uma postura crítico reflexiva sobre sua forma de ser e estar na sala de aula. $O$ processo de ser introduzido no ambiente de trabalho possibilita os licenciandos a conhecerem a realidade na qual irão atuar. Segundo Nóvoa (2009), a educação vive um momento de incertezas, pois reproduz discursos que se traduzem em poucas experiências práticas. Neste contexto, o autor evidencia a necessidade da formação de professores construída dentro da profissão, ou seja, repensar o contexto em si.

A prática docente caracteriza-se como uma teoria em ação. E como teoria em ação, mobiliza diferentes saberes constituídos nos processos de ensino e de aprendizagem do ambiente escolar. Segundo Tardif (2012) estes saberes são os saberes experienciais que são aprendidos e construídos na vivência da docência e modificam-se durante a carreira profissional. Os saberes experienciais mobilizam um conjunto de saberes: os saberes curriculares, disciplinares e científicos que são reconstruídos pelos docentes através da práxis. Nóvoa (1992) destaca a experiência no exercício da docência para além da dimensão didático/pedagógico, mas como um espaço de produção de saberes. Os saberes mobilizados na experiência vistos como teorias em ação geram novos saberes e são ressignificados e legitimados pelo coletivo de professores das escolas. 
As experiências aplicadas em sala de aula são oportunidades de aplicar os conceitos e os procedimentos adquiridos durante a formação do licenciando. Esses saberes adquiridos, segundo Tardif (2012), permitem que os professores reflitam sua formação através das situações cotidianas que se apresentam e transformem suas concepções acerca do fazer docente. Eles são constituídos através da experiência no exercício da docência, pois ao inserir os estudantes das licenciaturas nas escolas o PIBID possibilita uma reflexão acerca da prática docente que contribui na formação de sujeitos críticos/ reflexivos sobre sua constituição. Destaca-se ainda, em seus objetivos que os professores em exercício são vistos como co-formadores dos estudantes de licenciaturas, tornandoos protagonistas no processo de formação inicial (BRASIL, 2013).

A cada intervenção prática realizada, faz-se necessário uma análise reflexiva quanto ao seu desenvolvimento, juntamente com os outros integrantes do subprojeto e o professor coordenador. Quando fala-se no emprego de uma análise reflexiva entende-se que "[...] é preciso fazer um esforço grande para passar do nível meramente descritivo ou narrativo para o nível em que se buscam interpretações articuladas e justificadas e sistematizações cognitivas" (ALARCÃO, 2008, p. 45). Dessa forma, a noção de professor crítico está na condução do seu fazer pedagógico atrelado à capacidade do pensamento reflexivo do ser humano como criativo nas suas escolhas práticas.

Segundo as considerações destacadas através das enunciações da "Pibidiana", o PIBID oportuniza um novo olhar para as necessidades e preocupações com a profissão que a autora estava por seguir, de modo que, refletisse a prática e a partir disso, buscasse novas metodologias e também repensasse a atuação frente aos alunos. Stanzani (2012) salienta que esse Programa surge fundamentado nos resultados das pesquisas, também para suprir os espaços deixados no processo formativo e que tem possibilitado aos estudantes das licenciaturas melhores perspectivas quanto à profissão docente.

\section{CONSIDERAÇÕES FINAIS}

A falta de aproximação entre o cotidiano escolar com a formação inicial, muitas vezes, impossibilita os licenciandos de compreender as relações humanas que se constroem na dinâmica interativa e peculiar de cada instituição, movidas pelos processos de aprender e de ensinar, elementos essenciais ao papel da escola. Dessa forma, o PIBID proporciona aos licenciados a oportunidade de vivenciar atividades relacionadas à docência em seu processo de formação.

Como apresentado no decorrer do texto, o estudante passa a vivenciar a prática docente de forma muito mais rica e motivadora, integrando o conhecimento específico e pedagógico e, por fim, construindo sua identidade profissional como professor. Ressalta-se a importância para o desenvolvimento da identidade profissional obtida pelos licenciandos, uma vez que a "Pibidiana" destaca que teve experiências excelentes, das quais promoveu a integração entre educação superior e educação básica. 
Partindo das pressuposições apresentadas neste estudo, pode-se afirmar que o PIBID torna-se muito mais que um Programa de bolsas, pois através dos seus objetivos propostos, possibilita ao licenciando experiências enquanto docente, o que potencializa a qualidade na educação. Dessa forma, ratifica-se a importância do contato com a realidade educacional destacada através das enunciações de uma "Pibidiana".

\section{REFERÊNCIAS}

ALARCÃO, Isabel. Professores reflexivos em uma escola reflexiva. 6 ed. São Paulo: Cortez, 2008.

BRAIBANTE, M. E. F.; WOLLMANN, E. M. A Influência do PIBID na Formação dos Acadêmicos de Quí- mica Licenciatura da UFSM. Química Nova na Escola. v. 34, n.4, p. 167-172, 2012.

BRASIL. Ministério da Educação. Coordenação de Aperfeiçoamento de Pessoal do Ensino Superior. Portaria n. 096, de 18 de julho de 2013. Diário Oficial da União, Brasília, DF, 19 jul. 2013.

DELORS, J. Educação, um tesouro a descobrir. Relatório para a UNESCO da Comissão Internacional sobre Educação para o Século XXI. São Paulo: Cortez; Brasília: UNESCO, 1996.

FELÍCIO, H. M. S. O PIBID como "terceiro espaço" de formação inicial de professores. Revista Diálogo Educacional, Curitiba, v. 14, n. 42, maio/ago. 2014. Disponível em: <file:///D:/Downloads/dialogo-12752.pdf>. Acesso em: 20 jan. 2017.

GHEDIN, Evandro. Tendências e dimensões da formação na contemporaneidade. In: $4^{\circ} 460$ CONGRESSO NORTE PARANAENSE DE EDUCAÇÃO FÍSICA ESCOLAR (4o 461 CONPEF). 2009. Londrina. Anais...Londrina, UEL, 07-10 de jul. 2009.

IMBERNÓN, Francisco. Formação docente e profissional: formar-se para a mudança e a incerteza. 4. Ed. São Paulo, Cortez, 2004.

MARQUES, L. O. A formação docente no cotidiano escolar através do PIBID: um estudo com licenciadas do PIBID pedagogia FURG. 2015. 116 f. Dissertação (Mestrado em Educação) - Universidade Federal do Rio Grande, Rio Grande. 2015.

NÓVOA, A. (Org.). Vidas de Professores. Porto: Porto Editora, 1992 Formação de professores e profissão docente. In.: NÓVOA, António (coord.). Os

professores e a sua formação. 2 ed. Lisboa/PORT: Dom Quixote, Lda., 1995. p. 13-33.

Professores: imagens do futuro presente. Lisboa: Educa, 2009.

PÉREZ GÓMEZ, A. O Pensamento Prático do Professor: a formação do professor como prático reflexivo. In: NÓVOA, A. (Org.). Os professores e a sua formação. Lisboa: Dom Quixote, 1992. 
SILVA, Solange Mendes da. NUNES, Claudio Pinto. O PIBID como Política Pública de formação de professores. Revista Educação em Debate, Fortaleza, ano 38 - no 72 - jul./dez. 2016.

SOUZA, Celina. Políticas públicas: questões temáticas e de pesquisa. Caderno CRH, Salvador, v. 16, n. 39, p. 11-24, jul./dez. 2003.

STANZANI, E. L. O papel do PIBID na formação inicial de Professores de Química na Universidade Estadual de Londrina. Dissertação apresentada ao Programa de Pós-graduação em Ensino de Ciências e Educação Matemática da Universidade Estadual de Londrina, 2012.

TARDIF, M. Saberes Docentes e Formação Profissional. 14 o ed. Petrópolis, RJ. Editora Vozes, 2012. 